\title{
STATUS THERMAL COMFORT PADA LINGKUNGAN ATMOSFER PERMUKIMAN DI WILAYAH KECAMATAN DENPASAR BARAT
}

\author{
Komang Edy Indrawan Kusuma ${ }^{1 *)}$, I Wayan Kasa ${ }^{2)}$, I Nyoman Dhana ${ }^{3)}$ \\ 1)Badan Perencanaan Pembangunan Daerah Provinsi Bali \\ ${ }^{2)}$ Fakultas Matematika dan Ilmu Pengetahuan Alam, Universitas Udayana \\ ${ }^{3)}$ Fakultas Sastra, Universitas Udayana \\ *)Email: edy.indrawan@gmail.com
}

\begin{abstract}
The effect of residential atmosphere environment generally gives environment stress to the life of the dwellers. One of the environment stress source is the unfulfilment of thermal comfort. The rapid development of residential at Denpasar City cause the variation on building density that are low, medium, high, and very high density classifications. Residential configuration of each classification gives very strong influence to status of urban's thermal comfort. Purpose of the research is to understand the thermal index profile PET, to identify the status of thermal comfort and to analyze the influence of $\mathrm{T}_{\text {mrt }}$ to thermal index PET of residential atmosphere environment at West Denpasar Sub-district area. The research was performed at residential atmosphere environment of West Denpasar Sub-district area by using RayMan model simulation to obtain thermal index profile PET. Sampling technique used the stratified random sampling method with data diversity that is used based on the buildings density. The thermal index profile PET of residential of low density classification is the lowest thermal index profile PET compared to the other three classifications, which are the medium, high, and very high density. One hundred percent of status of thermal comfort of residential atmosphere environment is in hot thermal stress and based on average thermal index PET is on physiological stress level of "Strong heat stress". $\mathrm{T}_{\text {mrt }}$ is the most influential variable to thermal index PET. The concept to increase the status of thermal comfort of residential atmosphere environment at West Denpasar area used the bioclimatic approach. Investigation of status of thermal comfort of residential atmosphere environment at West Denpasar Sub-district area has given the directive of urban planning in improving and revitalized urban spaces.
\end{abstract}

Key words: Thermal Comfort, Thermal Index PET, Urban Bioclimatic, Atmosphere Environment

\section{PENDAHULUAN}

Salah satu faktor tekanan lingkungan pada manusia yang tinggal di daerah perkotaan adalah efek dari kondisi iklim artifisial, yang terjadi pada lingkungan eksternal terutama pada lingkungan binaan (Gulyas et al., 2003). Lingkungan eksternal memberikan efek signifikan pada kehidupan manusia, yang ditentukan oleh kondisi alami, faktor antropogenik, kepadatan bangunan perkotaan, dan ukuran area tutupan vegetasi (Kelmm, 2007 dalam Setaih et al., 2013). Pembangunan lingkungan binaan yang tidak memperhatikan kebutuhan fisik, psikologis dan sosial merupakan salah satu sumber tekanan lingkungan. Kebutuhan fisik bagi penghuni sebuah perkotaan salah satunya adalah thermal comfort, yang didefinisikan oleh American Society of Heating, Refrigerating, and Air-Conditioning Engineers (ASHRAE) (1966) dalam Epstein dan Moran (2006) sebagai kondisi pikiran yang mengekspresikan kepuasan terhadap lingkungan termal. Lingkungan termal pada ruang terbuka, pada kenyataannya, dipengaruhi oleh lingkungan binaan, melalui panas antropogenik (Ichinose et al.,
1999), tutupan permukaan tanah (Lin et al., 2007), evaporasi dan evapotranspirasi tanaman (Robitu et al., 2006), serta shading oleh pohon atau bangunan (Lin et al., 2010). Selain itu, lingkungan termal ruang terbuka perkotaan mempengaruhi konsumsi energi sebuah kota, dan prosesnya dalam penciptaan iklim perkotaan sangat kompleks (Latini et al., 2010).

Kota Denpasar dengan berbagai fungsinya baik sebagai kota pendidikan, perdagangan, pariwisata, dan ibu kota Provinsi Bali, menjadi daya tarik arus urbanisasi menyebabkan pertumbuhan penduduk demikian pesat. Kecamatan Denpasar Barat adalah kecamatan dengan kepadatan penduduk tertinggi yang mencapai $10.207 \mathrm{jiwa} / \mathrm{km}^{2}$ dengan laju pertumbuhan penduduk sebesar 2,02\% (Badan Pusat Statistik Kota Denpasar, 2014). Pertumbuhan penduduk di Kecamatan Denpasar Barat mengakibatkan pertumbuhan permukiman baru yang berakibat juga pada variasi kepadatan bangunan. Menurut data Badan Pusat Statistik (BPS) Kota Denpasar (2014) bahwa berdasarkan keadaan akhir Tahun 2012 dan keadaan akhir Tahun 2013 terjadi pertumbuhan bangunan sebesar 7.176 
bangunan. Dampaknya dapat berupa perkembangan infrastruktur pendukung pemukiman baru tersebut, baik jalan ataupun perkerasan lainnya yang memiliki sifat fisik permukaan yang beragam.

Penelitian bioklimatologi sangat jarang dilakukan di Indonesia terutamanya penelitian yang mengambil wilayah studi di Kota Denpasar. Hal ini menyebabkan data yang dibutuhkan untuk perencanaan kota dengan pendekatan bioklimatologi tidak tersedia. Masalah kenyamanan penduduk dan indeks bioklimatologi kuantitatif dapat memberikan informasi yang sangat penting untuk perencanaan Kota Denpasar khususnya Kecamatan Denpasar Barat, yang dapat membantu meningkatkan kesejahteraan (produktivitas) penduduk kota dengan perencanaan lingkungan yang sesuai dan sehat dan juga efisien dalam konsumsi energi. Penelitian sangat penting dilakukan untuk memberikan pedoman perencanaan perkotaan oleh perencana teknis dan pengambil keputusan (stakeholders) dengan cara yang tepat dan efektif menilai pembangunan perkotaan di Kecamatan Denpasar Barat, menargetkan RTHK yang lebih besar, meningkatkan dan merevitalisasi ruang perkotaan. Hal ini dapat dicapai dengan melakukan investigasi terlebih dahulu terhadap status thermal comfort lingkungan atmosfer permukiman dengan menggunakan pendekatan indeks termal PET. Tujuan penelitian adalah mengetahui profil indeks termal PET, mengidentifikasi status thermal comfort, dan menganalisis pengaruh $\mathrm{T}_{\text {mrt }}$ terhadap nilai indeks termal PET lingkungan atmosfer permukiman di wilayah Kecamatan Denpasar Barat.

\section{METODOLOGI}

Rancangan penelitian adalah penelitian analitik observasional dengan melakukan pengamatan terhadap lingkungan atmosfer permukiman secara cross-sectional dengan periode waktu pengamatan untuk memperoleh gambaran profil indeks termal PET. Penelitian menggunakan simulasi model RayMan untuk mendapatkan nilai indeks termal PET. Penelitian dilakukan di lingkungan atmosfer permukiman di wilayah kecamatan Denpasar Barat ditentukan secara purposive dengan pertimbangan lokasi penelitian merupakan kecamatan dengan kepadatan penduduk tertinggi di antara empat kecamatan di Kota Denpasar. Observasi lingkungan atmosfer dilakukan pada bulan Pebruari dan Maret 2015. Ruang lingkup penelitian ini adalah lingkungan atmosfer dengan klasifikasi biometeorologi manusia pada kompleks termal. Asumsi digunakan pada data termo-fisiologis, yaitu data produksi panas internal (Activity) dan resistensi transfer panas pakaian (Clo). Besaran nilai asumsi produksi panas internal yang digunakan yaitu $80 \mathrm{~W} /$ $\mathrm{m}^{2}$, setara dengan aktivitas manusia dengan kegiatan ringan sederhana pada posisi berdiri. Nilai asumsi resistensi transfer panas pakaian digunakan 0,50 clo untuk data personal pada pria berdasarkan SNI 036572-2001 (Badan Standar Nasional, 2001).

Untuk mendapatkan besaran sampel yang dapat mewakili populasi digunakan keragaman data berdasarkan kepadatan bangunan setiap permukiman (Tabel 1) dengan teknik pengambilan sampel menggunakan metode pengambilan sampel acak terstratifikasi (stratified random sampling). Instrumen penelitian adalah heat stress monitor (HSM), kamera DSLR Canon EOS 550D dan lensa Canon EF 8-15mm f/4L Fish-eye, Laptop, GPS, Meteran dan Kompas. Perangkat lunak yang digunakan adalah RayMan ver 1.2, SPSS ver. 20 dan Adobe Photoshop CS4. Analisis profil indeks termal PET dan status thermal comfort berdasarkan persepsi termal dan tingkat tekanan fisiologis menggunakan statistik deskriptif. Untuk

Tabel 1. Pembagian strata populasi penelitian

\begin{tabular}{|c|c|c|c|c|c|}
\hline Stasiun & Strata & Desa/Kelurahan & $\begin{array}{l}\text { Kepadatan Bangunan } \\
\text { Rata-rata }\end{array}$ & $\begin{array}{l}\text { Klasifikasi Kepadatan } \\
\text { Bangunan* }\end{array}$ & $\begin{array}{l}\text { Titik Koordinat } \\
\text { Sampling }\end{array}$ \\
\hline 1 & A & $\begin{array}{l}\text { - Padangsambian Klod } \\
\text { - } \quad \text { Pemecutan Klod } \\
\text { - } \text { Dauh Puri Klod } \\
\text { - Padangsambian } \\
\text { - Padangsambian Kaja }\end{array}$ & $30,04 /$ ha & Rendah & $\begin{array}{c}8^{\circ} 39^{\prime} 41.50^{\prime \prime} \mathrm{LS}, \\
115^{\circ} 10^{\prime} 41.46 " \mathrm{BT}\end{array}$ \\
\hline 2 & B & $\begin{array}{l}\text { - Dauh Puri Kauh } \\
\text { - Pemecutan }\end{array}$ & $47,98 / \mathrm{ha}$ & Sedang & $\begin{array}{l}8^{\circ} 39^{\prime} 23.42 " \mathrm{LS} \\
115^{\circ} 11^{\prime} 56.62 " \mathrm{BT}\end{array}$ \\
\hline 3 & C & Dauh Puri & $75,59 / \mathrm{ha}$ & $\begin{array}{c}\text { Tinggi } \\
115^{\circ} 12^{\prime} 41.54^{\prime \prime B T}\end{array}$ & $8^{\circ} 40^{\prime} 6.68 " \mathrm{LS}$ \\
\hline 4 & D & $\begin{array}{ll}\text { - } & \text { Tegal Harum } \\
\text { - } & \text { Tegal Kerta }\end{array}$ & $259,15 /$ ha & Sangat Padat & $\begin{array}{l}8^{\circ} 39^{\prime} 57.17^{\prime \prime L S} \\
115^{\circ} 11^{\prime} 49.88^{\prime \prime B T}\end{array}$ \\
\hline
\end{tabular}

Sumber: primer, $2015^{\star}$ Klasifikasi kepadatan bangunan berdasarkan Keputusan Menteri Pekerjaan Umum Nomor 378/KPTS/1987 tentang Pengesahan 33 Standar Konstruksi Bangunan Indonesia, Lampiran No. 22. 
menganalisis pengaruh nilai $\mathrm{T}_{\text {mrt }}$ terhadap nilai indeks termal PET menggunakan analisis regresi linier berganda.

\section{HASIL DAN PEMBAHASAN}

\subsection{Profil Indeks Termal PET}

Kondisi meteorologi skala mikro lingkungan atmosfer dengan temperatur udara tertinggi adalah sebesar $36{ }^{\circ} \mathrm{C}$ dan rata-ratanya sebesar $30,8^{\circ} \mathrm{C}$. Kelembaban udara tertinggi adalah sebesar $91,6 \%$ dan terendah sebesar $43,3 \%$. Kecepatan angin tertinggi sebesar $2,8 \mathrm{~m} / \mathrm{dt}$ dan terendah adalah sebesar $0,2 \mathrm{~m} / \mathrm{dt}$. Temperatur radiasi rata-rata tertinggi adalah sebesar $58,0^{\circ} \mathrm{C}$ dan terendah sebesar $43,8^{\circ} \mathrm{C}$. Setelah dilakukan simulasi menggunakan model RayMan, didapat indeks termal PET tertinggi sebesar $46,7^{\circ} \mathrm{C}$ dan terendah sebesar $25,7^{\circ} \mathrm{C}$.

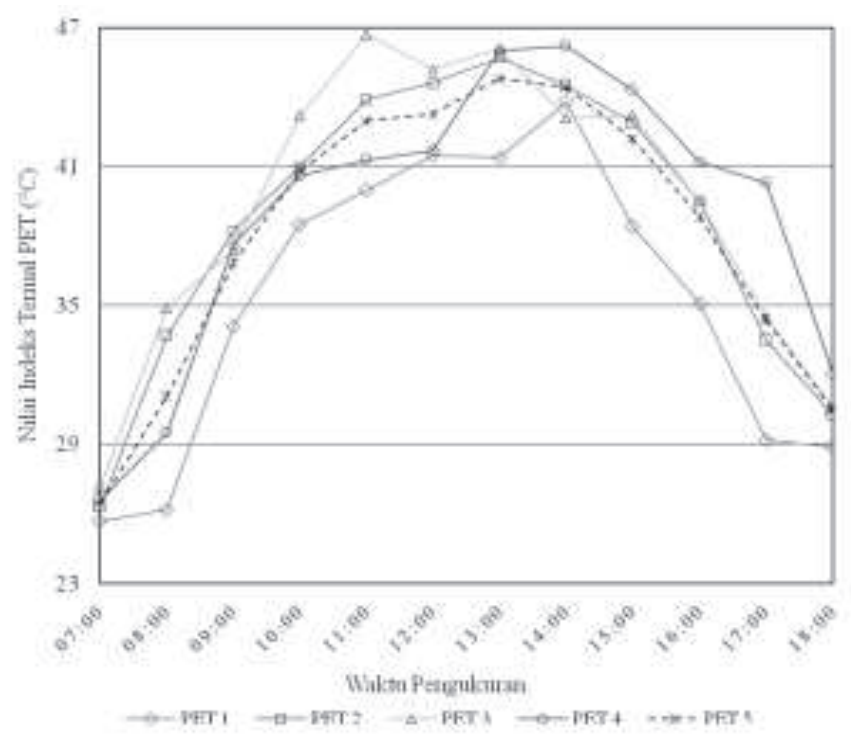

Gambar 1. Perbandingan profil indeks termal PET di setiap klasifikasi permukiman. PET 1: profil indeks termal PET pada klasifikasi rendah, $P E T 2$ : profil indeks termal PET pada klasifikasi sedang, PET 3 : profil indeks termal PET pada klasifikasi tinggi, PET 4 : profil indeks termal PET pada klasifikasi sangat padat dan PET 5 adalah rerata nilai indeks termal PET.

(Sumber : Hasil analisis data, 2015)

Profil indeks termal PET di permukiman dengan kepadatan bangunan rendah (Gambar 1. PET 1) menunjukkan bahwa nilai PET terendah yaitu sebesar $25,7^{\circ} \mathrm{C}$ dan mencapai nilai tertingginya sebesar $43,8^{\circ}$ yang termasuk dalam tingkatan persepsi termal "very hot". Distribusi nilai indeks termal PET di atas $41^{\circ} \mathrm{C}$ yang menunjukkan tingkatan persepsi termal "very hot" berlangsung selama tiga jam. Profil indeks termal PET di permukiman dengan kepadatan bangunan sedang (Gambar 1. PET 2) menunjukkan pola yang tidak jauh berbeda namun nilai PET terendah sebesar $26,73^{\circ} \mathrm{C}$ dan tertinggi sebesar $45,7^{\circ} \mathrm{C}$ yang termasuk dalam tingkatan persepsi termal "very hot". Distribusi nilai indeks termal PET di atas $41^{\circ} \mathrm{C}$ berlangsung selama lima jam.

Pola yang sama di kedua profil indeks termal PET menunjukkan pada tengah hari dengan intensitas radiasi yang lebih tinggi dibandingkan dengan pagi dan sore hari memiliki nilai indeks termal PET yang tinggi. Hal ini terjadi karena pada tengah hari radiasi matahari memberikan energi panas yang tinggi yang berasal dari fluks radiasi matahari gelombang pendek dan gelombang panjang dengan sudut datang yang besar terhadap permukaan. Pengaruh biometeorologi fluks radiasi matahari gelombang pendek dan gelombang panjang ditranspormasikan ke dalam parameter $\mathrm{T}_{\text {mrt }}$ (Wachter 1950; Bradkte 1951 dalam Matzarakis et al., 2007) di mana ditemukan pula pola profil $\mathrm{T}_{\text {mrt }}$ yang tinggi saat tengah hari (Gambar 2).

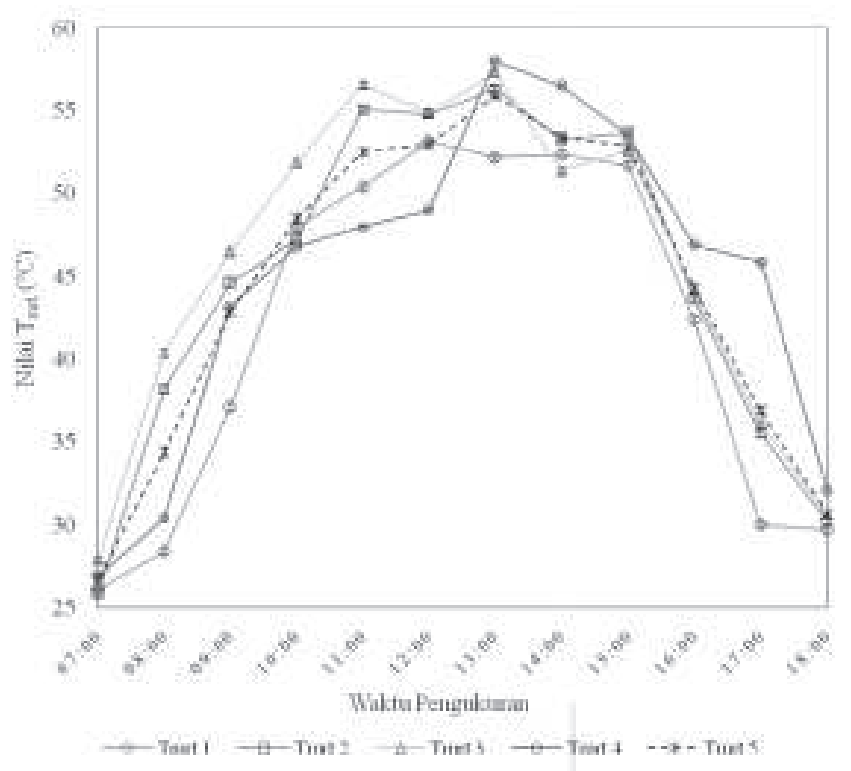

Gambar 2. Grafik perbandingan temperatur radiasi rata-rata. $T_{\text {mrt }} 1$ : temperatur radiasi rata-rata pada klasifikasi rendah, $T_{m r t} 2$ : temperatur radiasi rata-rata pada klasifikasi sedang, $T_{m+t} 3$ : temperatur radiasi rata-rata pada klasifikasi tinggi, $T_{m+t}^{m+1} 4$ : temperatur radiasi rata-rata klasifikasi sangat padat dan $\mathrm{T}_{\mathrm{mrt}}^{\mathrm{mrt}} 5$ : rerata temperatur radiasi rata-rata.

(Sumber : Hasil analisis data, 2015)

Profil indeks termal PET di permukiman dengan klasifikasi kepadatan bangunan tinggi (Gambar 1 . PET 3) tampaknya sedikit fluktuatif dibandingkan dua klasifikasi sebelumnya. Nilai PET terendah sebesar $27,2^{\circ} \mathrm{C}$ dan tertinggi sebesar $46,7^{\circ} \mathrm{C}$ yang juga termasuk dalam tingkat persepsi termal "very hot". Distribusi nilai indeks termal PET di atas $41^{\circ} \mathrm{C}$ berlangsung selama enam jam. Fluktuatifnya nilai indeks termal PET pada pukul 12:00 hingga pukul 15:00 disebabkan oleh fluktuasi nilai $\mathrm{T}_{\text {mrt }}$ (Gambar 2) dan hal yang paling memungkinkan untuk menjelaskan terjadinya fluktuatif ini adalah perubahan sesaat besaran fluks radiasi matahari 
gelombang panjang dan gelombang pendek saat pengukuran yang dapat disebabkan halangan sesaat radiasi matahari oleh tutupan awan. Tutupan awan mempengaruhi besaran fluks radiasi matahari gelombang pendek yang masuk dengan mengurangi kejadian ke permukaan bumi dan mengubah komposisi panjang gelombang sehingga relatif lebih banyak menjadi panjang gelombang terlihat (visible wavelengths) (Zhang et al., 1996; Van den Broeke et al., 2004 dalam Pellicciotti et al., 2011).

Profil nilai indeks termal PET di permukiman dengan klasifikasi kepadatan bangunan sangat padat (Gambar 1. PET 4) menunjukkan bahwa nilai PET terendah sebesar $26,6^{\circ} \mathrm{C}$ dan pada puncaknya sebesar $46,2^{\circ} \mathrm{C}$ yang termasuk juga dalam tingkatan persepsi termal "very hot". Distribusi nilai indeks termal PET di atas $41^{\circ} \mathrm{C}$ berlangsung selama enam jam. Nilai indeks termal PET permukiman klasifikasi sangat padat pada pagi hingga tengah hari tercatat lebih rendah dibandingkan dengan nilai indeks termal PET klasifikasi kepadatan sedang dan tinggi dan bahkan pada beberapa titik waktu pengukuran yaitu pukul 08:00, 10:00, 11:00 dan 12:00 lebih rendah dibandingkan rerata indeks termal PET. Parameter $\mathrm{T}_{\text {mrt }}$ adalah penyebab kondisi nilai indeks termal PET permukiman klasifikasi kepadatan sangat padat pada saat pagi hingga tengah hari lebih kecil dibandingkan dengan indeks termal PET permukiman klasifikasi sedang dan tinggi (lihat Gambar 2) Diperkirakan fluks radiasi matahari gelombang pendek di titik pengukuran permukiman klasifikasi sangat padat saat pagi hingga tengah hari mempunyai nilai yang jauh lebih kecil dibandingkan saat tengah hari hingga sore hari. Perbedaan besaran nilai fluks radiasi gelombang pendek dapat terjadi di wilayah perkotaan. Matzarakis (2001) dalam Matzarakis et al. (2007) menyatakan bahwa fluks radiasi matahari gelombang pendek adalah parameter meteorologi yang memiliki variasi yang sangat besar di wilayah perkotaan.

\subsection{Status Thermal Comfort}

Status thermal comfort lingkungan atmosfer permukiman di wilayah Kecamatan Denpasar Barat $100 \%$ berada dalam tekanan termal panas panas dengan rentang dari slight heat stress sampai dengan extreme heat stress. Jika dilihat berdasarkan rerata indeks termal PET pada permukiman klasifikasi rendah, sedang, tinggi dan sangat padat masingmasing yaitu $35,23^{\circ} \mathrm{C}, 38,68^{\circ} \mathrm{C}, 39,30^{\circ} \mathrm{C}$, dan $38,95^{\circ} \mathrm{C}$, maka kondisi tingkat tekanan fisiologis berada pada tingkat "Strong heat stress". Persentase tekanan fisiologis termal masing-masing klasifikasi dapat dilihat pada Gambar 3. Namun hal ini berlaku untuk lingkungan atmosfer yang berada di luar naungan bayangan pepohonan dan bangunan yang merupakan obyek penelitian ini. Sebagaimana diketahui bahwa penelitian Mayer dan Matzarakis (1998) menunjukkan terjadi penurunan tingkat tekanan termal manusia pada siang hari, ketika radiasi matahari langsung dinaungi oleh pohon dengan perbedaan nilai rata-rata $\mathrm{PET}$ sebesar $15^{\circ} \mathrm{C}$.
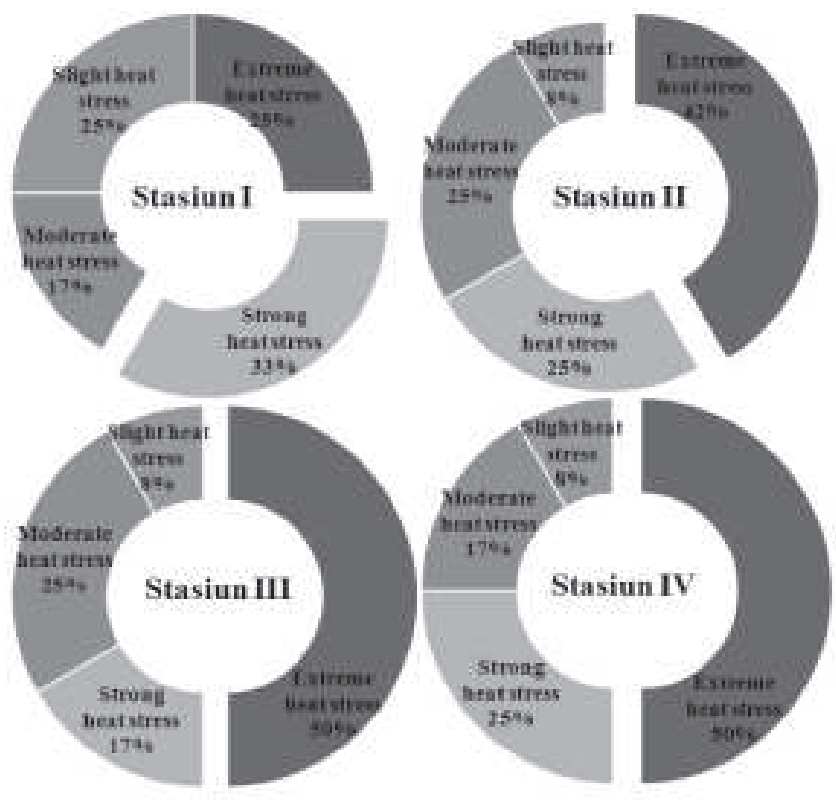

Gambar 3. Grafik tekanan fisiologis manusia di permukiman wilayah Kecamatan Denpasar Barat (Sumber : Hasil analisis data, 2015)

Tekanan termal panas akan lebih sering terjadi dan meningkat di masa yang akan datang dalam kaitannya dengan perubahan iklim global (Matzarakis dan Endler, 2010), sebagaimana laporan IPCC (2007) bahwa diperkirakan terjadi peningkatan temperatur udara sebesar lebih dari $3^{\circ} \mathrm{C}$ pada akhir abad ke-21. Berdasarkan analisis yang ditunjukkan dalam Tabel 2, bahwa rerata indeks termal PET pada akhir abad ke-21 di permukiman wilayah Kecamatan Denpasar Barat klasifikasi kepadatan bangunan rendah, sedang, tinggi dan sangat padat adalah sebesar masing-masing $37,5^{\circ} \mathrm{C}, 40,3^{\circ} \mathrm{C}, 42,5^{\circ} \mathrm{C}$ dan $40,7^{\circ} \mathrm{C}$. Meskipun perubahan status thermal comfort pada akhir abad ke-21 hanya terjadi pada permukiman klasifikasi kepadatan tinggi dengan status thermal comfort menjadi tingkat tekanan fisiologis extreme heat stress, namun nilai rerata indeks termal PET permukiman sedang $\left(40,3^{\circ} \mathrm{C}\right)$ dan sangat padat $\left(40,7^{\circ} \mathrm{C}\right)$ berada pada nilai yang sangat dekat dengan batas tingkat tekanan fisiologis extreme heat stress yaitu $41^{\circ} \mathrm{C}$.

Paparan termal panas dengan tingkat tekanan fisiologis extreme heat stress, akan memberikan konsekuensi terhadap kesehatan penduduk. Respon fisiologis terhadap kondisi ini adalah terjadinya proses vasodilatasi untuk meningkatkan pengeluaran panas dari tubuh dengan meningkatkan aliran darah ke permukaan kulit sehingga temperatur permukaan kulit meningkat dan disertai dengan peningkatan sekresi keringat. Saat temperatur inti tubuh melewati $38-39^{\circ} \mathrm{C}$, terjadi peningkatan resiko pengeluaran panas, dan dengan 
Tabel 2. Prediksi rerata indeks termal PET dan status thermal comfort di wilayah Kecamatan Denpasar Barat pada akhir abad ke-21

\begin{tabular}{lcccccc}
\hline Model & $\begin{array}{c}\text { Rerata } \\
\text { Temperatur } \\
\text { Udara }\left({ }^{\circ} \mathrm{C}\right)\end{array}$ & $\begin{array}{c}\text { Perkiraan } \\
\text { Temperatur Udara } \\
\text { padaAkhirAbad } \\
\text { ke-21 }\left({ }^{\circ} \mathrm{C}\right)\end{array}$ & $\begin{array}{c}\text { Koefisien } \\
\text { regresi }(\mathrm{B}) \\
\text { Temperatur Udara }\end{array}$ & $\begin{array}{c}\text { Rerata Indeks } \\
\text { Termal PET Hasil } \\
\text { Pengukuran }\left({ }^{\circ} \mathrm{C}\right)\end{array}$ & $\begin{array}{c}\text { Prediksi Rerata } \\
\text { Indeks Termal PET } \\
\text { padaAkhirAbad } \\
\mathrm{ke}-21^{* *}\left({ }^{\circ} \mathrm{C}\right)\end{array}$ & $\begin{array}{c}\text { Tingkat Tekanan } \\
\text { Fisiologis padaAkhir } \\
\text { Abad ke-21 }\end{array}$ \\
\hline 1 & 30,8167 & 33,8167 & 0,734 & 35,2333 & 37,435 & Strong heat stress \\
2 & 32,8250 & 35,8250 & 0,544 & 38,6750 & 40,307 & Strong heat stress \\
3 & 33,3167 & 36,3167 & 1,050 & 39,3000 & 42,450 & Extreme heat stress \\
4 & 33,0083 & 36,0083 & 0,567 & 38,9500 & 40,651 & Strong heat stress \\
\hline
\end{tabular}

* Dihitung berdasarkan perkiraan kenaikan T $3^{\circ} \mathrm{C}$ dalam laporan IPCC tahun 2007

** Diasumsikan parameter kelembaban udara, kecepatan angin dan temperatur radiasi rata-rata tidak berubah

Sumber : Hasil analisis data, 2015

temperatur di luar dari itu dapat menimbulkan heat stroke yang dapat berakhir dengan kegagalan sistem termoregulasi saraf pusat (Jay dan Kenny, 2010 dalam Lundgren et al., 2013). Konsekuensi kesehatan lainnya berupa dehidrasi, cedera, kelelahan akibat panas, penyakit kardiovaskuler, katarak, gagal ginjal, melemahnya sistem kekebalan tubuh, dan kematian. (WHO, 2012 dalam Lundgren et al., 2013).

\subsection{Pengaruh $T_{\text {mrt }}$ terhadap Indeks Termal PET}

Hasil ANOVA pada analisis statistik menunjukkan variabel $T_{a}, R H, v$ dan $T_{m r t}$ berpengaruh secara simultan terhadap indeks termal PET. Pengujian secara parsial pengaruh variabel $\mathrm{T}_{\mathrm{mrt}}$ terhadap variabel indeks termal PET menunjukkan variabel $\mathrm{T}_{\text {mrt }}$ berpengaruh positif terhadap indeks termal PET. Hasil uji statistik menunjukkan variabel $\mathrm{T}_{\text {mrt }}$ adalah variabel yang paling berpengaruh terhadap indeks termal PET lingkungan atmosfer permukiman di setiap klasifikasi kepadatan bangunan terkecuali di klasifikasi kepadatan bangunan rendah, variabel $\mathrm{T}_{\text {mrt }}$ bersama dengan variabel $\mathrm{v}$ adalah variabel yang paling berpengaruh signifikan.

Persamaan regresi model 1 (permukiman klasifikasi rendah) menjadi:

$\mathrm{Y}_{1}=-8,601+0,734 \mathrm{~T}_{\mathrm{a}}+0,031 \mathrm{RH}-1,417 \mathrm{v}+0,492 \mathrm{~T}_{\text {mrt }}$ (1) Persamaan regresi model 2 (permukiman klasifikasi sedang) menjadi :

$\mathrm{Y}_{2}=-1,171+0,544 \mathrm{~T}_{\mathrm{a}}+0,001 \mathrm{RH}-0,868 \mathrm{v}+0,508 \mathrm{~T}_{\text {mrt }}$ (2) Persamaan regresi model 3 (permukiman klasifikasi tinggi) menjadi:

$\mathrm{Y}_{3}=-16,626+1,050 \mathrm{~T}_{\mathrm{a}}+0,041 \mathrm{RH}-1,169 \mathrm{v}+0,436 \mathrm{~T}_{\mathrm{m}+\mathrm{t}}$ (3) Persamaan regresi model 4 (permukiman klasifikasi sangat padat) menjadi :

$\mathrm{Y}_{4}=-1,827+0,567 \mathrm{~T}_{\mathrm{a}}+0,001 \mathrm{RH}-1,121 \mathrm{v}+0,510 \mathrm{~T}_{\mathrm{mrt}}$

\subsection{Metode Meningkatkan Status Thermal Comfort Permukiman di Wilayah Denpasar Barat}

Proses perencanaan permukiman dengan pendekatan bioklimatik telah dimulai dengan pemahaman terhadap kondisi iklim mikro lingkungan atmosfer permukiman di wilayah Kecamatan Denpasar Barat. Pendekatan bioklimatik dalam desain permukiman di wilayah Kecamatan Denpasar Barat dimulai dengan strategi penempatan, orientasi dan shading bangunan untuk mendapatkan aliran angin dengan kecepatan yang maksimal yang dapat menurunkan nilai indeks termal PET. Hasil analisis menunjukkan bahwa orientasi East-West memiliki rerata kecepatan angin tertinggi sebesar $1,1483 \mathrm{~m} / \mathrm{dt}$.

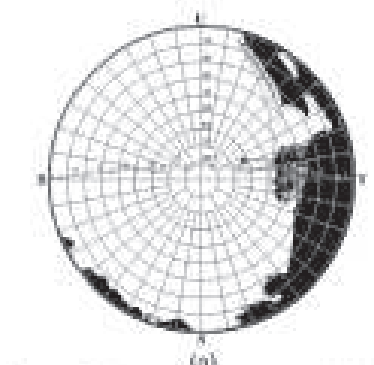

Hovison lowioxione

Sky wese fower

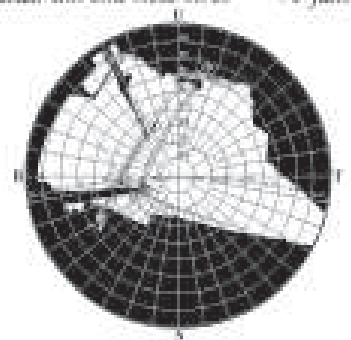

$(\mathrm{c})$

Howsan Lawionom

Sky wew facwer

Durasi atrewe heo sws

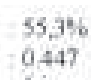

$55,3 \%$
0,447

6 jam
Dumbi edreme how sines $\quad 3$ jum

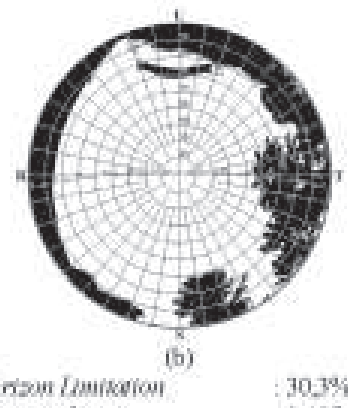

Howsen Lemisovion Sy vene Gacto Duras cernene heo sines : 5 farm

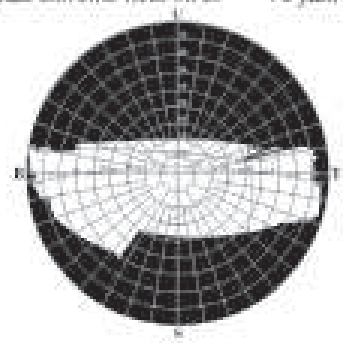

(d)

Hanvar Lemisgion

Sy view focsor

Durasi coneme fiex stres

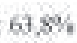

0,362
Gambar 4. Nilai horizon limitation, SVF dan durasi extreme heat stres di lokasi penelitian. (a) Stasiun I; (b) Stasiun II; (c) Stasiun III; dan (d) Stasiun IV (sumber : hasil analisis data, 2015)

Keseimbangan termal yang ingin dicapai pada lingkungan atmosfer permukiman di wilayah Denpasar Barat dalam menyerap panas saat siang hari dan melepaskan panas saat malam hari ditentukan oleh susunan bangunan-bangunan yang melingkupi ruang atmosfer yang ditunjukkan dari 
nilai Horizon limitation, SVF dan durasi extreme heat stres (Gambar 4). Hasil analisis menunjukkan nilai SVF yang lebih tinggi memberikan peluang paparan radiasi matahari berdurasi yang lebih panjang namun demikian memiliki keseimbangan antara penerimaan (heat gain) dan pelepasan panas (heat loss) yang lebih baik.

Aspek geometri lainnya yang dipertimbangkan adalah rasio $\mathrm{H} / \mathrm{W}$ permukiman di lokasi penelitian yang berkisar antara 1,0-1,5. Lin et al. (2009) dalam Afiq et al. (2012) menemukan bahwa terdapat pengurangan kecepatan angin terendahnya sebesar empat kali dari magnitudo aliran angin bebas pada rasio $\mathrm{H} / \mathrm{W}=3$. Pengurangan kecepatan angin ini diakibatkan dari timbulnya vortex baru pada sudut bawah bangunan di belakang aliran angin yang bergerak menuju tengah ngarai sebelum vortex lainnya muncul di tempat yang sama. Berbanding terbalik dengan peningkatan rasio $\mathrm{H} / \mathrm{W}$, kecepatan angin di permukaan ngarai jalan berkurang drastis. Dengan demikian perencanaan rasio $\mathrm{H} / \mathrm{W}$ permukiman di Kecamatan Denpasar Barat sebaiknya adalah $\mathrm{H} / \mathrm{W}<3$, dengan kata lain dengan lebar jalan permukiman berkisar antara dua sampai tiga meter, maka ketinggian bangunan tidak lebih dari enam sampai sembilan meter.

Langkah berikutnya adalah memikirkan konsep desain bioklimatik dalam perencanaan permukiman, yaitu: (1) Merencanakan zona penyangga hijau (Green buffer) merupakan sebuah upaya dalam membuat lingkungan yang melingkupi permukiman dengan materi hijau yang terbukti efeknya dalam meningkatkan iklim mikro. Zona penyangga hijau dapat direncanakan secara bertahap pada lahanlahan kosong terbentang sepanjang wilayah timur Desa Padangsambian Kaja hingga wilayah utara Desa Pemecutan Kelod; (2) Menempatkan tanaman perindang di sepanjang jalan permukiman untuk memberikan efek pendinginan udara melalui shading. Keterlibatan partisipasi masyarakat dalam penyediaan pohon perindang sangat diperlukan terutamanya Desa Tegal Harum dan Desa Tegal Kerta yang sangat padat; (3) Menempatkan titik-titik ruang terbuka hijau skala kecil dapat diterapkan di wilayah permukiman Desa Tegal Harum dan Desa Tegal Kerta yang merupakan permukiman sangat padat dalam wujud lansekap berbentuk tamantaman mini yang tidak membutuhkan ruang terlalu besar; (4) . Menyediakan kolam tampungan skala besar yang sangat baik dalam penyerapan panas yang membantu peningkatan thermal comfort lingkungan atmosfer permukiman di wilayah Denpasar Barat. Wilayah yang memiliki potensi untuk digunakan sebagai lokasi kolam tampungan skala besar adalah Desa Pemecutan Kelod yang berdekatan dengan tiga sumber air permukaan, yaitu Tukad Badung, Tukad Teba dan Tukad Mati; (5) pengunaan fitur-fitur air seperti air mancur, kolam air, aliran air dan air dangkal pada ruang terbuka dapat menghilangkan panas perkotaan yang ekstrem melalui sistem pendinginan evaporatif (Stavrakakis et al., 2012). Fitur-fitur air ini dapat diterapkan di lokasi-lokasi lansekap yang tersebar di wilayah permukiman Denpasar Barat; (6) Penggunaan material yang memiliki albedo tinggi dengan kemampuan permukaan untuk memantulkan radiasi matahari yang masuk pada lingkungan permukiman adalah teknik yang sangat efektif untuk mengurangi efek dari lingkungan termal (Fintikakis et al., 2011). Untuk penggunaan material jalan permukiman di wilayah Denpasar Barat sangat baik menggunakan material paving beton yang memiliki nilai albedo yang lebih tinggi $(0,3)$ dibandingkan dengan aspal $(0,1)$, yang memiliki nilai reflektansi lebih tinggi dibanding aspal. Fasade bangunan permukiman sebaiknya menggunakan warna-warna putih dan terang; dan (7) Penggunaan elemen-elemen fisik berupa perangkat shading buatan seperti pergola dan lain sebagainya, menyediakan shading dengan menghalangi radiasi matahari langsung yang mempengaruhi atmosfer termal ruang luar dan karenanya mempengaruhi sensitivitas termal ruang luar (Lin et al., 2010). Elemen shading ini dapat digunakan pada pedestrian permukiman yang memiliki tingkat mobilisasi pejalan kaki yang tinggi, di ruang tunggu depan sekolah dan gedung perkantoran, dan ruang-ruang terbuka publik lainnya.

\section{SIMPULAN DAN SARAN}

\subsection{Simpulan}

Penelitian Status Thermal Comfort pada Lingkungan Atmosfer Permukiman di wilayah Kecamatan Denpasar Barat memperoleh tiga simpulan yaitu: (1) Profil indeks termal PET lingkungan atmosfer permukiman dengan klasifikasi kepadatan bangunan rendah adalah profil yang terendah dibandingkan dengan klasifikasi sedang, tinggi dan sangat padat; (2) Status thermal comfort lingkungan atmosfer permukiman di wilayah Denpasar Barat berada dalam tingkat prosentase $100 \%$ mengalami tekanan termal panas dengan rentang tingkat tekanan fisiologis "slight heat stress" sampai dengan "extreme heat stress". Berdasarkan rerata indeks termal PET didapat persepsi termal "hot" dan tingkat tekanan fisiologis "strong heat stress"; dan (3) $\mathrm{T}_{\text {mrt }}$ berpengaruh positif terhadap indeks termal PET di semua klasifikasi permukiman menurut kepadatan bangunan di wilayah Kecamatan Denpasar Barat dan merupakan variabel yang paling berpengaruh dibandingkan dengan variabel lainnya. 


\subsection{Saran}

Berdasarkan hasil analisis penelitian dan simpulan, maka dapat disarankan sebagai berikut:

1) Saran bagi perencana perkotaan dan Pemerintah Kota Denpasar

a. Perencanaan permukiman di wilayah Kecamatan Denpasar Barat setidaknya harus memperhatikan parameter meteorologi skala mikro.

b. Strategi penempatan orientasi ngarai jalan permukiman dan bukaan permukiman di wilayah Kecamatan Denpasar Barat sebaiknya berorientasi terhadap arah mata angin East-West.

c. Untuk memperoleh keseimbangan termal lingkungan atmosfer maka kepadatan bangunan permukiman yang direncanakan sebaiknya memiliki klasifikasi kepadatan bangunan rendah dengan nilai SVF yang tinggi.

d. Rasio H/W dalam perencanaan permukiman di wilayah Kecamatan Denpasar Barat sebaiknya kurang dari tiga.

e. Metode peningkatan thermal comfort yaitu zona penyangga hijau, tanaman perindang, lansekap taman-taman mini, kolam tampungan skala besar, fitur-fitur air, material albedo tinggi, dan perangkat shading buatan,sangat diperlukan dalam perencanaan permukiman.

f. Meninjau kembali pemanfaatan ruang dalam Rencana Detail Tata Ruang Kecamatan Denpasar Barat sehingga dapat mengakomodasi rencana zona penyangga hijau dan rencana tampungan air skala besar

2) Saran bagi masyarakat

a. Penduduk Kota Denpasar disarankan merencanakan bangunan tempat tinggal dengan komposisi koefisien dasar bangunan (KDB) sedang (40 - 50 \%) sehingga nilai SVF permukiman menjadi tinggi.

b. Partisipasi masyarakat dalam menyediakan tanaman perindang dan lansekap tamantaman mini (baik taman horisontal maupun taman vertikal) pada lahan milik pribadi.

c. Partisipasi masyarakat dalam penggunaan warna putih dan cerah untuk fasade bangunan tempat tinggal dan material bangunan yang memiliki reflektansi tinggi terhadap radiasi matahari.

d. Menghindari aktivitas outdoor dengan paparan radiasi matahari secara langsung yang berlebihan pada pukul 10:00 sampai dengan pukul 14:00 yang dapat merugikan kesehatan.

e. Penggunaan pakaian pelindung diri saat terpapar radiasi matahari yang berlebihan. f. Penggunaan teknologi pendingin udara yang ramah lingkungan di lingkungan indoor permukiman untuk mengantisipasi dampak konduksi dan konveksi panas dari lingkungan outdoor permukiman.

3) Saran untuk penelitian selanjutnya

a. Diperlukan penelitian status thermal comfort untuk Kecamatan Denpasar Timur, Kecamatan Denpasar Utara dan Kecamatan Denpasar Selatan sehingga dapat menyediakan data bagi perencanaan perkotaan dengan pendekatan bioklimatik secara menyeluruh dan terintegrasi di wilayah Kota Denpasar.

b. Diperlukan penelitian tentang rerata tingkat metabolisme (W) dan rerata tingkat insulasi pakaian (Clo) penduduk di Kota Denpasar sehingga penelitian status thermal comfort berikutnya tidak menggunakan nilai asumsi.

c. Diperlukan penelitian tentang KDB bangunan rumah tinggal optimal yang dapat memberikan thermal comfort dengan status tingkat persepsi termal netral.

\section{DAFTAR PUSTAKA}

Afiq W.M.Y., Azwadi C.S.N., dan K.M. Saqr. 2012. Effects of Buildings Aspect Ratio, Wind Speed and Wind Direction on Flow Structure and Pollutant Dispersion in Symmetric Street Canyons: a Review. International Journal of Mechanical and Materials Engineering (IJMME), Vol. 7 (2012), No. 2, 158-165.

Badan Pusat Statistik Kota Denpasar. 2014. Denpasar Dalam Angka 2014. Denpasar, Badan Pusat Statistik Kota Denpasar.

Badan Standar Nasional. 2001. SNI 03-6572-2001: Tata cara perancangan sistem ventilasi dan pengkondisian udara pada bangunan gedung. Jakarta.

Epstein, Y and Moran, D. S. 2006. Thermal Comfort and the Heat Stress Indices. Industrial Health 2006, 44, 388-398.

Fintikakis, N., Gaitani, N., Santamouris, M., Assimakopoulos, M., Assimakopoulos, D.N., Fintikaki, M., Albanis, G., Papadimitriou, K., Chryssochoides, E., Katopodi, K. and Doumas, P. 2011. Bioclimatic Design of Open Public Spaces in the Historic Centre of Tirana, Albania. Journal of Sustainable Cities and Society, 1, 5462.

Gulyas, A., Unger, J., Balazs, B., and Matzarakis, A. 2003. Analysis of the Bioclimatic Conditions within Different Surface Structures in a Medium- 
Sized City (Szeged, Hungary). Acta Climatologica et Chorologica, Universitatis Szegediensis, Tom. 36-37, 37-44.

Ichinose, T., Shimodozno, K., and Hanaki, K. 1999. Impact of Anthropogenic Heat on Urban Climate in Tokyo. Atmos. Env. 33:3897-909.

IPCC. 2007. Climate Change 2007: Impact, Adaptation, and Vulnerability. Contribution of Working Group II to the Fourth Assessment Report of the IPCC. Cambridge, Cambridge University Press.

Latini, G., Grifoni, R.C., and Tascini, S. 2010. Thermal Comfort and Microclimates in Open Spaces. ASHRAE: Building XI Conference CD.

Lin, T.P., Ho, Y.F., and Huang, Y.S. 2007. Seasonal Effect of Pavement on Outdoor Thermal Environments in Subtropical Taiwan. Journal of Building and Environment 42:4124-31.

Lin, T.P., Matzarakis, A.,and Hwang, R.L. 2010. Shading Effect on Long-term Outdoor Thermal Comfort. Journal of Building and Environment 45(1):213-221.

Lundgren, K., Kuklane, K., Gao, C., and Holmér, I. 2013. Effects of Heat Stress on Working Populations when Facing Climate Change. Industrial Health 2013, 51.

Matzarakis, A. and Endler, C. 2010. Climate change and thermal bioclimate in cities: impacts and options for adaptation in Freiburg, Germany. Int J Biometeorol 54:479-483

Matzarakis, A., Rutz, F. and Mayer, H., 2007. Modelling radiation fluxes in simple and complex environments - application of the RayMan model. Int J Biometeorol 51:323-334
Mayer, H. and Matzarakis, A. 1998. Humanbiometeorological assessment of urban microclimates' thermal component. In: Proceedings 2nd Japanese-German Meeting “Klimaanalyse für die Stadtplanung”, Special rep 1, pp 155-168.

Menteri Pekerjaan Umum. 1987. Keputusan Menteri Pekerjaan Umum Nomor 378/KPTS/1987 tentang Pengesahan 33 Standar Konstruksi Bangunan Indonesia. Lampiran No. 22.

Pellicciotti, F., Raschle, T., Huerlimann, T., Carenzo, M. and Burlando, P. 2011. Transmission of solar radiation through clouds on melting glaciers: a comparison of parameterizations and their impact on melt modelling. Journal of Glaciology, Vol. 57, No. 202. 367-381.

Robitu, M., Musy, M., Inard, C., and Groleau, D. 2006. Modeling the Influence of Vegetation and Water Pond on Urban Microclimate. Journal of Solar Energy 80:435-47.

Setaih, K., Hamza, N., and Townshend, T. 2013. Assessment of Outdoor Thermal Comfort in Urban Microclimate in Hot Arid Areas. In: 13th Conference of International Building Performance Simulation Association, France, August 26 - 28. Chambery, 3153 - 3160.

Stavrakakis, G.M., Tzanaki, E., Genetzaki, V.I., Anagnostakis, G., Galetakis, G. and Grigorakis, E. 2012. A Computational Methodology for Effective Bioclimatic-Design Applications in the Urban Environment. Journal of Sustainable Cities and Society, 4, 41-57. 